\title{
Ring-opening polymerization of $\varepsilon$-caprolactone with dilithium tetra-tert-butylzincate under mild conditions
}

\author{
Miyuki Oshimura, Ryo Okazaki, Tomohiro Hirano and Koichi Ute
}

We performed ring-opening polymerization (ROP) of $\varepsilon$-caprolactone with dilithium tetra-tert-butylzincate (TBZL) in toluene. TBZL is a bulky zincate complex with a range of unique reactivities such as unusually low basicity and high chemoselectivity; it is a metal catalyst of low toxicity. The initiating species for ROP of $\varepsilon$-caprolactone is, however, not the tert-butyl anion of TBZL but the hydroxyl anion derived from a trace amount of $\mathrm{H}_{2} \mathrm{O}$ in the system. Instead of a trace amount of $\mathrm{H}_{2} \mathrm{O}$ in the system, a known amount of benzyl alcohol $(\mathrm{BnOH})$ was added as an ROP initiator. Poly( $\varepsilon$-caprolactone) with a BnO group at the initiating chain-end was obtained, as expected. ${ }^{1} \mathrm{H}$ and ${ }^{13} \mathrm{C}$ NMR spectra of a TBZL-BnOH mixture suggested the formation of a complex; the complex was the initiating species. The $M_{\mathrm{n}}$ increased linearly with increasing conversion. This means that the number of polymer chains is constant throughout the polymerization. The molecular weight distributions were relatively narrow, except with increased temperatures and/or prolonged polymerization times. This system does not need a high polymerization temperature or long polymerization time and uses a metal compound that has little effect on the environment. Poly $(\varepsilon-$ caprolactone) with a narrow molecular weight distribution can therefore be obtained under mild conditions. Polymer Journal (2014) 46, 866-872; doi:10.1038/pj.2014.76; published online 27 August 2014

\section{INTRODUCTION}

Aliphatic polyesters have received much attention because of their biodegradability and biocompatibility. Poly( $\varepsilon$-caprolactone) (PCL), in particular, is used industrially and medically. PCL is usually prepared by ring-opening polymerization (ROP) of $\varepsilon$-caprolactone, catalyzed by metal compounds, enzymes, organic compounds or inorganic compounds. ${ }^{1}$ Mechanisms for ROP of $\varepsilon$-caprolactone are generally classified into four categories, depending on the catalyst: anionic, cationic, monomer-activated, or coordination-insertion ROP. Although each initiation system has advantages and disadvantages, broadening of the molecular weight distribution derived from intramolecular transesterification (back-biting), generally occurring in the later stages of anionic ROP, is especially unfavorable.

Living anionic ROP of $\varepsilon$-caprolactone with another metal catalyst, namely a combination of tert-butyllithium and bulky aluminum phenoxide, was reported to give polymers with narrow molecular weight distributions. ${ }^{2}$ In that study, the tert-butyl anion initiated ROP of $\varepsilon$-caprolactone and aluminum phenoxide coordinated with the carbonyl carbon of the $\varepsilon$-caprolactone monomer. The ROP proceeded in a living manner because the bulky aluminum phenoxide stabilized the propagating species to prevent transesterification.

Here, we report the ROP of $\varepsilon$-caprolactone catalyzed by dilithium tetra-tert-butylzincate (TBZL), which is a metal catalyst of low toxicity. TBZL is a bulky zincate complex that has a range of unique reactivities such as unusually low basicity and high chemoselectivity. ${ }^{3-6}$ TBZL acts as an anionic initiator for the polymerization of
$\mathrm{N}$-isopropylacrylamide in aqueous media ${ }^{3,6}$ or in toluene in the presence of a fluorinated alcohol or Lewis acid. ${ }^{6}$

On the basis of these previous reports, we considered that the ROP of $\varepsilon$-caprolactone with TBZL would also proceed by an anionic mechanism, with the tert-butyl anion of TBZL acting as an anionic initiator. In the present paper, the polymerization mechanism of ROP with TBZL was investigated using ${ }^{1} \mathrm{H}$ and ${ }^{13} \mathrm{C}$ nuclear magnetic resonance (NMR) spectroscopies, size-exclusion chromatography (SEC) and matrix-assisted laser desorption-ionization time-of-flight mass spectrometry (MALDI-TOFMS). These characterizations of the obtained PCL suggested that the initiating species for ROP of $\varepsilon$-caprolactone with TBZL is not the tert-butyl anion of TBZL, and unexpectedly, the ROP proceeded by a coordination-insertion mechanism.

\section{EXPERIMENTAL PROCEDURE}

\section{Materials}

$\varepsilon$-Caprolactone ( $>99 \%$ ) was purchased from the Tokyo Chemical Industry (Tokyo, Japan) and distilled before use. Benzyl alcohol (BnOH; > 99\%) was purchased from Wako Pure Chemical Industries (Osaka, Japan) and distilled before use. Toluene (super dehydrated; $>99.5 \%$ ), tetrahydrofuran (THF, super dehydrated; $>99.5 \%$ ), lithium chloride (>99\%) and zinc chloride (>99.9\%) were purchased from Wako Pure Chemical Industries. A THF solution of TBZL was supplied by the Tosoh Finechem (Yamaguchi, Japan). tert-Butyllithium ( ${ }^{\mathrm{t}} \mathrm{BuLi} ; 1.65 \mathrm{moll}^{-1}$ in pentane), lithium bis(trifluoromethanesulfonyl)imide $\left(\mathrm{LiN}\left(\mathrm{SO}_{2} \mathrm{CF}_{3}\right)_{2} ; 99.7 \%\right)$ and $n$-hexane $(>95 \%)$ were purchased from the Kanto Chemical (Tokyo, Japan). 

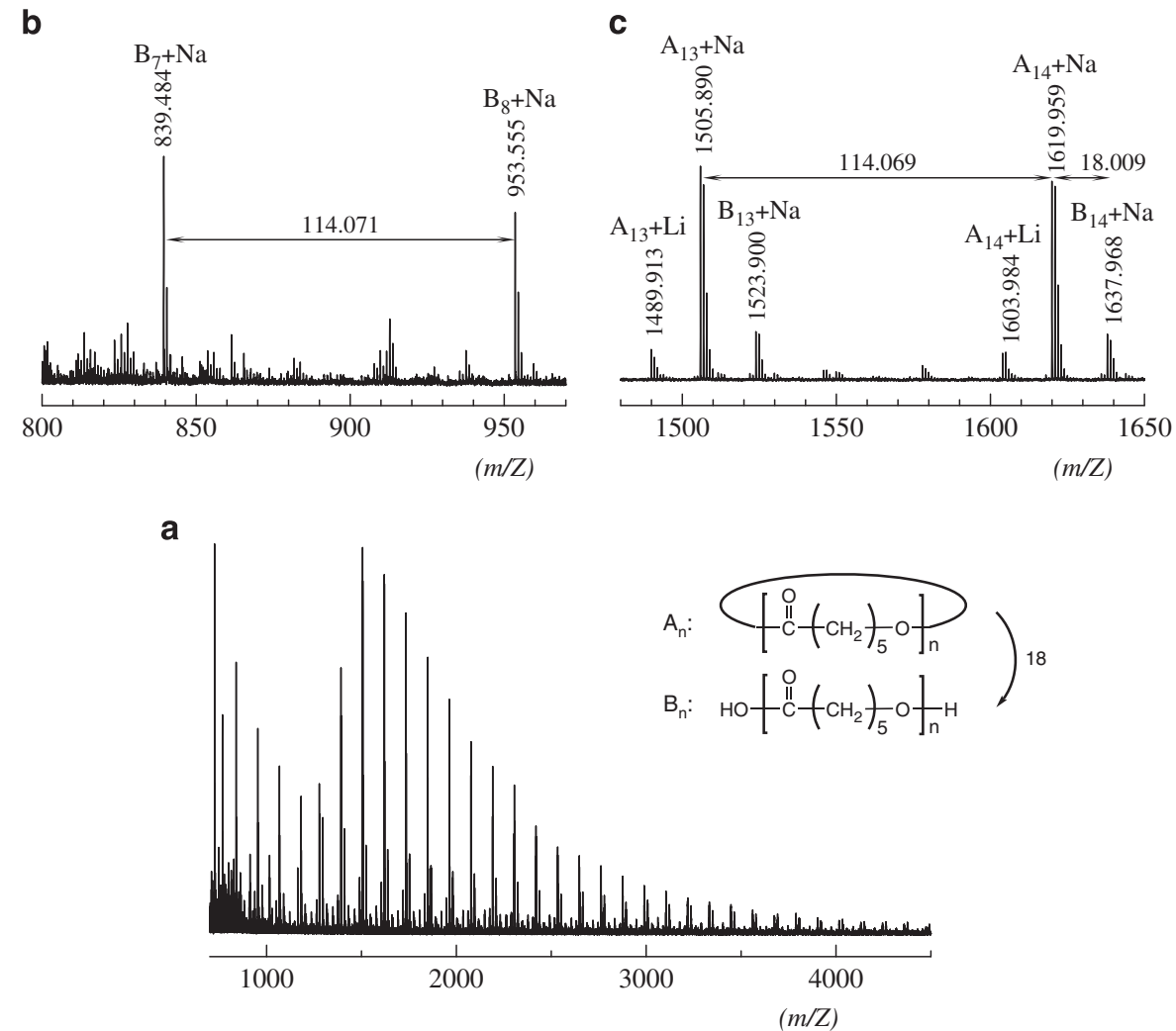

Figure 1 (a) MALDI-TOF mass spectrum of PCL prepared with TBZL. Expanded spectra at the range of 800-970 m/Z (b), and of 1480-1650 m/Z (c).

\section{Measurements}

The $400-\mathrm{MHz}{ }^{1} \mathrm{H}$ NMR spectra were obtained using an ECX-400 spectrometer (JEOL, Tokyo, Japan). The number-average molecular weights $\left(M_{\mathrm{n}}\right)$ and the polydispersity indexes $\left(M_{\mathrm{w}} / M_{\mathrm{n}}\right)$ of the polymers were determined using SEC, calibrated against polystyrene standards. SEC was performed using an HLC 8220 chromatograph (Tosoh, Yamaguchi, Japan) equipped with TSK gel columns (SuperHM-M $(6.5 \mathrm{~mm} \mathrm{ID} \times 150 \mathrm{~mm})$ and SuperHM-H $(6.5 \mathrm{~mm}$ ID $\times 150 \mathrm{~mm})$, Tosoh). Dimethylformamide containing $\operatorname{LiBr}\left(10 \mathrm{mmoll}^{-1}\right)$ was used as the eluent, at $40^{\circ} \mathrm{C}$ and a flow rate of $0.35 \mathrm{ml} \mathrm{min}^{-1}$. The initial polymer concentration was $1.0 \mathrm{mg} \mathrm{ml}^{-1}$. MALDI-TOFMS was performed using an Autoflex Speed-TK spectrometer (Bruker Daltonics, Billerica, MA, USA) with dithranol and $\mathrm{NaI}$ as the matrix and ionizing agent, respectively. The zinc and lithium contents of the THF solution of TBZL were determined by titration.

\section{Concentration of TBZL solution}

A THF solution of TBZL $(\sim 0.500 \mathrm{ml})$ was added to aqueous $\mathrm{HCl}(\mathrm{N} / 2$, $\sim 10.00 \mathrm{ml}$ ) containing phenolphthalein as a $\mathrm{pH}$ indicator. The solution was titrated with an aqueous solution of $\mathrm{NaOH}(\mathrm{N} / 2)$. This procedure was repeated three times.

$$
\operatorname{TBZL}\left(\mathrm{moll}^{-1}\right)=\frac{\left(M_{\mathrm{HCl}} \times V_{\mathrm{HCl}}-M_{\mathrm{NaOH}} \times V_{\mathrm{NaoH}}\right)}{V_{\mathrm{TBZL}}} \times \frac{1}{4}
$$

TBZL contains four tert-butyl anions and reacts with a fourfold molar amounts of acid. The concentration of the TBZL solution was determined using the above equation. $M_{\mathrm{HCl}}, V_{\mathrm{HCl}}, M_{\mathrm{NaOH}}, V_{\mathrm{NaOH}}$ and $V_{\mathrm{TBZL}}$ are the molar concentrations of $\mathrm{HCl}$, the added $\mathrm{HCl}$ volume, the molar concentration of $\mathrm{NaOH}$, the added $\mathrm{NaOH}$ volume and the TBZL volume, respectively. The titration and inductively coupled plasma optical emission spectroscopy showed that the THF solution of TBZL (base: $0.626 \mathrm{moll}^{-1}$ ) contained $3.6 \mathrm{wt} \% \mathrm{zinc}$ and $1.4 \mathrm{wt} \%$ lithium.

\section{ROP of $\varepsilon$-caprolactone with TBZL}

A typical polymerization procedure was as follows. $\varepsilon$-Caprolactone $(0.5 \mathrm{~g}$, $4.4 \mathrm{mmol}$ ) was diluted with toluene to a total volume of $5 \mathrm{ml}$, and this solution
( $4 \mathrm{ml}$ ) was transferred to a glass ampoule. The ampoule was degassed and filled with nitrogen three times. TBZL $\left(0.11 \mathrm{ml}, 0.626 \mathrm{moll}^{-1}\right.$ in THF solution) was added under a nitrogen atmosphere to the ampoule, which had been placed in a constant-temperature bath. Then the mixture was stirred. After the reaction, the mixture was diluted with THF and poured into $n$-hexane $(200 \mathrm{ml})$. The polymer precipitate was collected by centrifugation and dried in vacuo. The polymer yield was determined gravimetrically.

\section{Preparation of ${ }^{t} \mathrm{Bu}_{4} \mathrm{ZnLi}_{2}$ and ${ }^{t} \mathrm{Bu}_{2} \mathrm{Zn}$}

${ }^{t} \mathrm{Bu}_{4} \mathrm{ZnLi}_{2}$ and ${ }^{t} \mathrm{Bu}_{2} \mathrm{Zn}$ were prepared by the addition of 4 or 2 molar amounts, respectively, of ${ }^{t} \mathrm{BuLi}\left(1.65 \mathrm{moll}^{-1}\right.$ in pentane) relative to $\mathrm{ZnCl}_{2}$ in THF.,

$$
\begin{aligned}
& 4{ }^{t} \mathrm{BuLi}+\mathrm{ZnCl}_{2} \rightarrow{ }^{t} \mathrm{Bu}_{4} \mathrm{ZnLi}_{2}+2 \mathrm{LiCl} \\
& 2{ }^{t} \mathrm{BuLi}+\mathrm{ZnCl}_{2} \rightarrow{ }^{t} \mathrm{Bu}_{2} \mathrm{Zn}+2 \mathrm{LiCl}
\end{aligned}
$$

\section{RESULTS AND DISCUSSION}

\section{ROP of $\varepsilon$-caprolactone with TBZL}

First, we attempted the ROP of $\varepsilon$-caprolactone with TBZL in toluene at $0{ }^{\circ} \mathrm{C}$. The initial monomer concentration $\left([\mathrm{M}]_{0}\right)$ and the $[\mathrm{M}]_{0} /[\mathrm{TBZL}]_{0}$ ratio were $1 \mathrm{moll}^{-1}$ and 50 , respectively. The polymer was obtained at $94 \%$ yield in $10 \mathrm{~min} . M_{\mathrm{n}}$ and $M_{\mathrm{w}} / M_{\mathrm{n}}$ of the polymer were determined by SEC to be $9.0 \times 10^{3}$ and 2.01, respectively. The ${ }^{1} \mathrm{H}$ NMR spectrum indicated the formation of PCL via ROP of $\varepsilon$-caprolactone (Supplementary Figure S1). However, the resonance from the tert-butyl end group at 1.13 p.p.m. ${ }^{2}$ was not observed in the PCL spectrum, although the tert-butyl anion of TBZL has been reported to initiate polymerization of $\mathrm{N}$-isopropylacrylamide. ${ }^{3-6}$ The MALDI-TOF mass spectrum of the PCL showed two series of peaks, both at an interval of $114 \mathrm{~m} / Z$, corresponding to the repeating unit mass (Figure 1). The $m / Z$ values for the series with higher mass numbers (series A) agreed well with the monoisotopic masses of the 


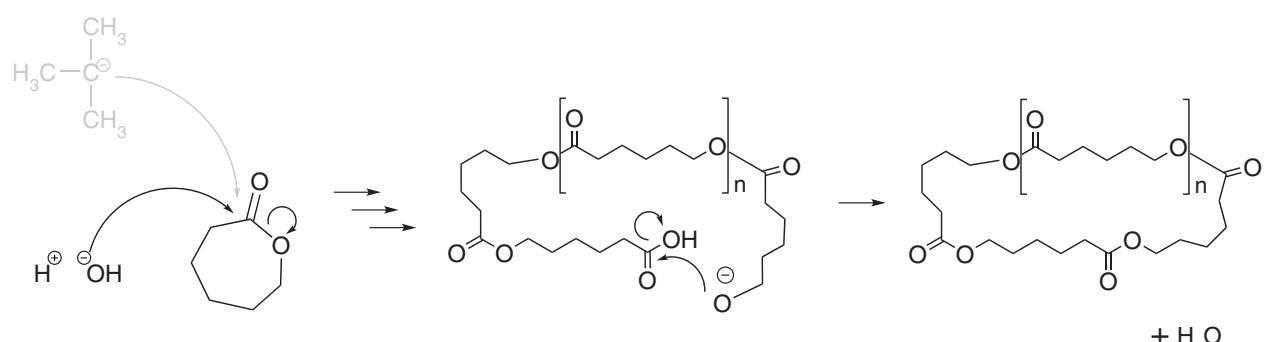

Scheme 1 Possible mechanism of cyclic PCL formation by ROP.

Table 1 ROP of $\varepsilon$-caprolactone with TBZL in the presence of $\mathrm{BnOH}$ in toluene

\begin{tabular}{|c|c|c|c|c|c|c|c|c|}
\hline \multirow[b]{2}{*}{ Run } & \multirow{2}{*}{$\begin{array}{l}{[\mathrm{M}]_{O}} \\
\left(\mathrm{~mol} / \mathrm{I}^{-1}\right)\end{array}$} & \multirow{2}{*}{$\begin{array}{l}{[\mathrm{M}]_{O} /[\mathrm{TBZL}]_{O}} \\
{[\mathrm{BnOH}]_{O}}\end{array}$} & \multirow{2}{*}{$\begin{array}{l}\text { Temp. } \\
\text { ( } \mathrm{C})\end{array}$} & \multirow{2}{*}{$\begin{array}{l}\text { Time } \\
\text { (h) }\end{array}$} & \multirow{2}{*}{$\begin{array}{l}\text { Yield } \\
(\%)\end{array}$} & \multicolumn{2}{|c|}{$M_{n} \times 10^{-3}$} & \multirow{2}{*}{$\begin{array}{l}M_{w} J \\
M_{n}{ }^{\mathrm{b}}\end{array}$} \\
\hline & & & & & & Calcd & $N M R^{a}$ & \\
\hline 1 & 1.0 & $50 / 1 / 1$ & 20 & 1 & 94 & 5.5 & 3.9 & 1.60 \\
\hline 2 & 1.0 & $50 / 1 / 1$ & 0 & 1 & 89 & 5.2 & 4.2 & 1.17 \\
\hline 3 & 1.0 & $50 / 1 / 1$ & -20 & 1 & 25 & 1.5 & 1.8 & 1.10 \\
\hline 4 & 1.0 & $50 / 1 / 1$ & -40 & 1 & Trace & - & - & - \\
\hline 5 & 2.0 & $400 / 1 / 4$ & 0 & $40 \mathrm{~min}$ & 85 & 9.8 & 19.6 & 1.23 \\
\hline $6^{c}$ & 2.0 & $400 / 1 / 4$ & 0 & 24 & 0 & - & - & - \\
\hline $7^{d}$ & 2.0 & $400 / 1 / 4$ & 0 & 24 & 0 & - & - & - \\
\hline $8^{e}$ & 2.0 & $400 / 1 / 4$ & 0 & 1 & 92 & 10.6 & 9.2 & 1.13 \\
\hline $9^{f}$ & 2.0 & $400 / 1 / 4$ & 0 & 24 & 0 & - & - & - \\
\hline $10^{g}$ & 2.0 & $400 / 1 / 4$ & 0 & $40 \mathrm{~min}$ & 73 & 8.4 & 13.5 & 1.37 \\
\hline
\end{tabular}

a Determined by ${ }^{1} \mathrm{H}$ NMR spectroscopy (in $\mathrm{CDCl}_{3}$ ) intensity ratio.

betermined by SEC in DMF, calibrated using standard PSs.

${ }^{C} \mathrm{LiCl}$ was used as a catalyst instead of TBZL.

d $\mathrm{LiN}\left(\mathrm{SO}_{2} \mathrm{CF}_{3}\right)_{2}$ was used as a catalyst instead of TBZL.

et $\mathrm{Bu}_{4} \mathrm{ZnLi}_{2}$ prepared by ourselves was used a catalyst.

${ }^{\mathrm{ft}} \mathrm{Bu}_{2} \mathrm{Zn}$ was used as a catalyst instead of TBZL.

$\mathrm{g} \mathrm{BnOH}$ was premixed with TBZL for $15 \mathrm{~min}$ before adding $\varepsilon$-caprolactone.

$\mathrm{Na}^{+}$adducts of cyclic PCL ( for example, $n=13, M_{\text {theor }}=1505.875$, $\left.M_{\text {obs }}=1505.890\right)$. The $m / Z$ values for the series with lower mass numbers (series B) agreed well with the monoisotopic masses of the $\mathrm{Na}^{+}$adducts of PCLs with a carboxyl group and a hydroxyl group at each chain-end (for example, $n=13, M_{\text {theor }}=1523.885$, $\left.M_{\mathrm{obs}}=1523.900\right)$.

These results suggest that the initiating species for ROP of $\varepsilon$-caprolactone is not the tert-butyl anion of TBZL but the hydroxyl anion derived from a trace amount of $\mathrm{H}_{2} \mathrm{O}$ in the system. In other words, TBZL behaved not as an initiator but as a catalyst. PCL with a carboxyl group at the initiating chain-end and a hydroxyl group at the terminating chain-end was therefore considered to be produced preferentially. Furthermore, it was assumed that cyclic PCL was formed as a result of intramolecular condensation between the carboxyl and hydroxyl terminals (Scheme 1).

\section{ROP of $\varepsilon$-caprolactone with TBZL in the presence of $\mathrm{BnOH}$}

Instead of a trace amount of $\mathrm{H}_{2} \mathrm{O}$ in the system, a known amount of $\mathrm{BnOH}$ was added as an ROP initiator. The results of the ROP of $\varepsilon$-caprolactone in the presence of $\mathrm{BnOH}$ and TBZL are summarized in Table 1 . The $[\mathrm{M}]_{0}$ and $[\mathrm{M}]_{0} /[\mathrm{TBZL}]_{0} /[\mathrm{BnOH}]_{0}$ ratios were $1-2 \mathrm{moll}^{-1}$ and $50 / 1 / 1$ to $400 / 1 / 4$, respectively. ROP of $\varepsilon$-caprolactone in toluene at $20^{\circ} \mathrm{C}$ gave a polymer with a broad molecular weight distribution (run 1). When the polymerization temperature

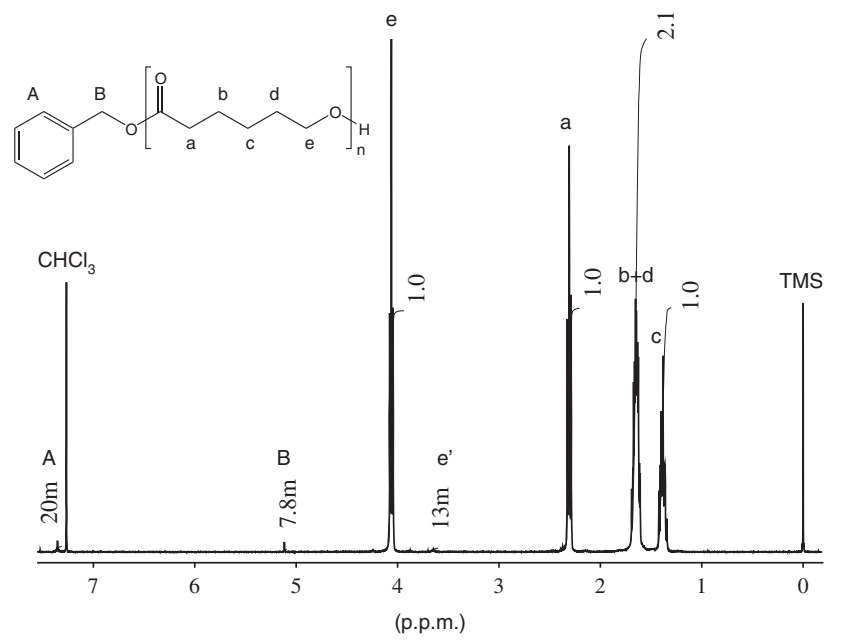

Figure $2{ }^{1} \mathrm{H}$ NMR spectrum of PCL prepared with TBZL in presence of $\mathrm{BnOH}$ (run 5, in $\mathrm{CDCl}_{3}$ at $25^{\circ} \mathrm{C}$ ).

was decreased, the polymer yields and $M_{\mathrm{w}} / M_{\mathrm{n}}$ values of the polymers that were obtained (runs 2 and 3) decreased. Polymerization at $-40^{\circ} \mathrm{C}$ gave no polymer (run 4 ).

In the ${ }^{1} \mathrm{H}$ NMR spectrum of the polymer obtained at $0{ }^{\circ} \mathrm{C}$, benzyl group resonances were observed at 5.12 and $7.33-7.37$ p.p.m. (Figure 2). The MALDI-TOF mass spectrum of the polymer showed a set of peaks at an interval of $114 \mathrm{~m} / \mathrm{Z}$ (Figure 3 ), and the values were consistent with the monoisotopic masses of $\mathrm{Na}^{+}$adducts of PCL with a $\mathrm{BnO}$ group at the initiating chain-end and a hydroxyl group at the terminating chain-end (series C, for example, $n=20$, $\left.M_{\text {theor }}=2412.409, M_{\text {obs }}=2412.549\right)$. However, a set of peaks corresponding to the monoisotopic masses of $\mathrm{Na}^{+}$adducts of PCLs with a carboxyl group and a hydroxyl group at each end (series B, for example, $n=7, M_{\text {theor }}=839.477, M_{\text {obs }}=839.501$ ) was observed in the lower mass region. These results indicate that $\mathrm{BnOH}$ can initiate the ROP of $\varepsilon$-caprolactone catalyzed by TBZL, as expected. In addition, cyclic PCL was not obtained by ROP in the presence of $\mathrm{BnOH}$. The mechanism of generation of cyclic PCL in the absence of $\mathrm{BnOH}$ is not definite at the present stage. However, these results suggested that the cyclic PCL obtained by $\mathrm{H}_{2} \mathrm{O}$-initiated ROP was formed by an intramolecular condensation between the carboxyl and hydroxyl terminals.

TBZL is considered to be a tetrahedral dianion-type zincate, ${ }^{t} \mathrm{Bu}_{4} \mathrm{Zn}^{2-} \mathrm{Li}^{+}{ }_{2} \cdot{ }^{5}$ It was assumed that $\mathrm{Li}^{+}$in TBZL acted as a Lewis acid catalyst in this polymerization system. $\mathrm{LiCl}$ or $\mathrm{LiN}\left(\mathrm{SO}_{2} \mathrm{CF}_{3}\right)_{2}$ was therefore added instead of TBZL to examine the effect of $\mathrm{Li}^{+}$on ROP of $\varepsilon$-caprolactone. However, neither $\mathrm{LiCl}$ nor $\mathrm{LiN}\left(\mathrm{SO}_{2} \mathrm{CF}_{3}\right)_{2}$ exhibited 

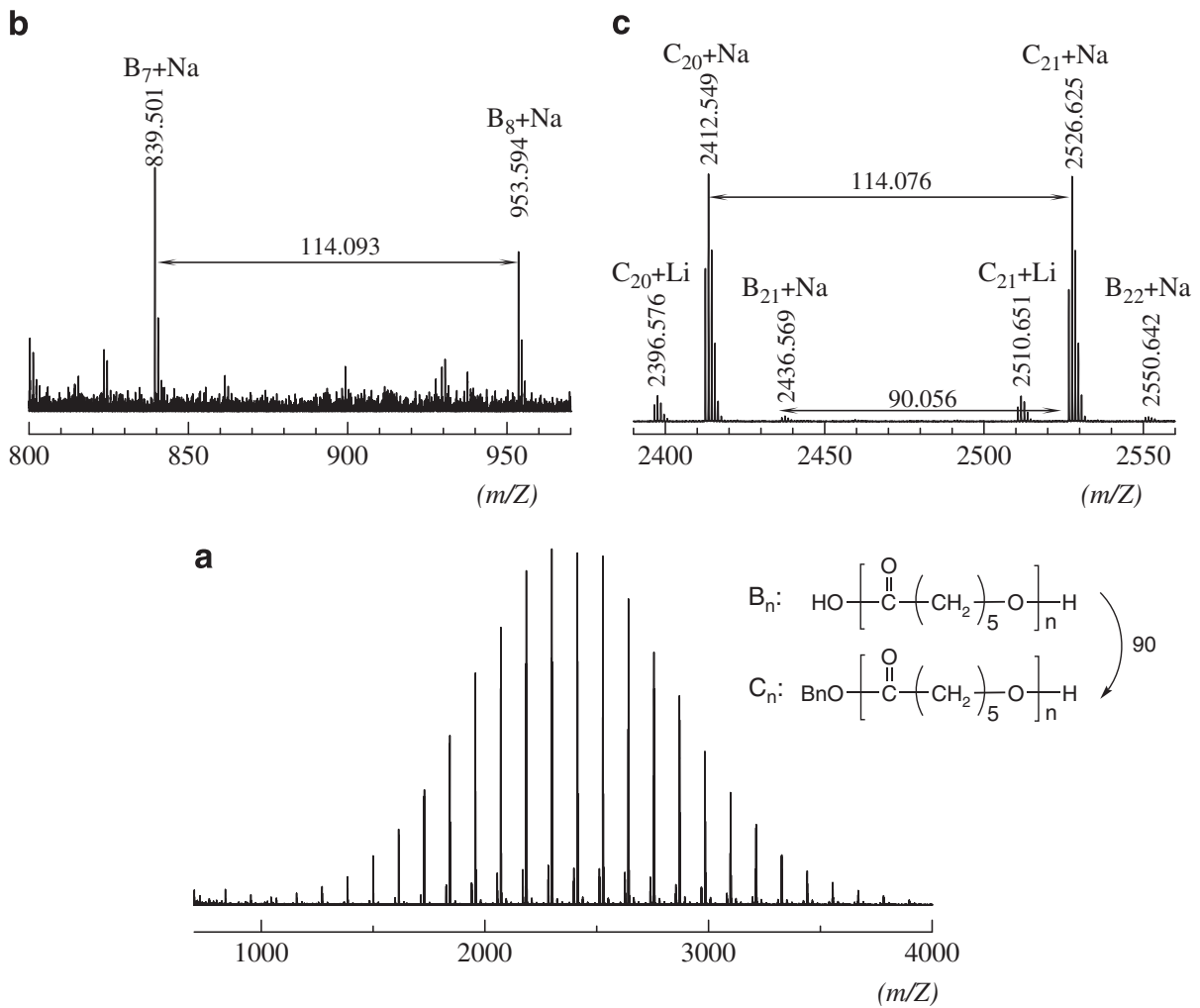

Figure 3 (a) MALDI-TOF mass spectrum of PCL prepared with TBZL in presence of $\mathrm{BnOH}$ (run 5). Expanded spectra at the range of $800-970 \mathrm{~m} / \mathrm{Z}$ (b), and of $2390-2560 \mathrm{~m} / \mathrm{Z}$ (c).

any catalytic activity in the ROP of $\varepsilon$-caprolactone, even with longer polymerization times (runs 6 and 7).

Figure 4 (top) shows the time-conversion curve for polymerization with an initial monomer concentration of $[\mathrm{M}]_{0}$ and $[\mathrm{M}]_{0} /[\mathrm{TBZL}]_{0} /$ $[\mathrm{BnOH}]_{0}$ ratios of $2 \mathrm{moll}^{-1}$ and 400/1/4, respectively (run 5). After $5 \mathrm{~min}$ of initiation, an aliquot was removed from the reaction mixture, using a syringe, by flushing with $\mathrm{N}_{2}$ gas; the aliquot was mixed with $\mathrm{CDCl}_{3}$ for NMR spectroscopy or with $n$-hexane to precipitate the polymer for SEC (sample a). Similar procedures were performed after 10, 15, 20, 30 and 40 min of initiation (samples b-f, respectively). The monomer conversion was determined from the integral intensities of the NMR signals of the $-\mathrm{CH}_{2}-\mathrm{O}-\mathrm{CO}-$ methylene protons in the monomer and polymer. The $M_{\mathrm{n}, \mathrm{NMR}}$ values were estimated by chain-end analysis of the NMR signals of the benzyl protons and those of the $-\mathrm{CH}_{2}-\mathrm{O}-\mathrm{CO}-$ methylene protons based on the assumption that polymerization was initiated by $\mathrm{BnOH}$ only. The time-conversion curve and $\ln \left([\mathrm{M}]_{0} /[\mathrm{M}]\right)$ versus time plots suggest that there was a significant induction period, probably because of slow initiation, but the polymerization rate after the induction period was first order with respect to the monomer concentration. Similar behaviors were observed in the ROP of $\varepsilon$-caprolactone with aluminum alkoxides ${ }^{7,8}$ or commercial yttrium isopropoxide. ${ }^{9}$ The $M_{\mathrm{n}}$ increased linearly with increasing conversion. This means that the number of polymer chains is constant throughout the polymerization.

The SEC profile of sample a was unimodal and a narrow molecular weight distribution was observed (Figure $5, M_{\mathrm{w}} / M_{\mathrm{n}}=1.08$ ). As the polymerization proceeded, the shoulder in the higher molecular weight region increased, resulting in an increase in $M_{\mathrm{w}} / M_{\mathrm{n}}$. This suggests that nucleophilic attack by the hydroxyl group at the terminating chain-end occurs preferentially at the carbonyl carbon on $\varepsilon$-caprolactone rather than at the carbonyl carbon on the polymer main chain and intermolecular esterification took place to a certain extent. Similar observations have been reported for the ROP of $\delta$-valerolactone using trifluoromethanesulfonimide as a catalyst at high monomer concentrations. ${ }^{10}$ Although intramolecular condensation between the carboxyl and hydroxyl terminals was suppressed, intramolecular transesterification between the hydroxyl and carbonyl terminals on the polymer main chain arise slightly after monomer consumption. So, those shoulders in SEC become bigger and bigger. With lower monomer concentration $\left([\mathrm{M}]_{0}=1 \mathrm{moll}^{-1}\right)$, SEC chart of the PCL did not have definite shoulder at the latter term of the ROP.

\section{Proposed mechanism of $\varepsilon$-caprolactone polymerization catalyzed} by TBZL

The mechanism of the ROP of $\varepsilon$-caprolactone catalyzed by TBZL was investigated. ${ }^{1} \mathrm{H}$ NMR of the supplied TBZL solution indicated that the TBZL solution included not only ${ }^{t} \mathrm{Bu}_{4} \mathrm{ZnLi}_{2}$ but also ${ }^{t} \mathrm{Bu}_{2} \mathrm{Zn}$ (Figure 6a). To clarify the actual catalyst, ${ }^{t} \mathrm{Bu}_{4} \mathrm{ZnLi}_{2}$ and ${ }^{t} \mathrm{Bu}_{2} \mathrm{Zn}$ were prepared separately by the addition of 4 and 2 molar amounts, respectively, of ${ }^{t} \mathrm{BuLi}$ relative to $\mathrm{ZnCl}_{2} .{ }^{3,4}$ The ${ }^{1} \mathrm{H}$ NMR spectra confirmed the successful synthesis of ${ }^{t} \mathrm{Bu}_{4} \mathrm{ZnLi}_{2}$ and ${ }^{t} \mathrm{Bu}_{2} \mathrm{Zn}$ (Figures $6 \mathrm{~b}$ and $\mathrm{c}$ ). The ROPs of $\varepsilon$-caprolactone catalyzed by the obtained ${ }^{t} \mathrm{Bu}_{4} \mathrm{ZnLi}_{2}$ and ${ }^{t} \mathrm{Bu}_{2} \mathrm{Zn}$ were performed. $\varepsilon$-Caprolactone was hardly consumed in the ROP catalyzed by ${ }^{t} \mathrm{Bu}_{2} \mathrm{Zn}$, even after $24 \mathrm{~h}$ (run 9). In contrast, ${ }^{t} \mathrm{Bu}_{4} \mathrm{ZnLi}_{2}$ catalyzed the ROP of $\varepsilon$-caprolactone (run 8 ). Furthermore, the $\ln \left([\mathrm{M}]_{0} /[\mathrm{M}]\right)$ versus time plots indicated that there is an induction period in the ROP catalyzed by the ${ }^{t} \mathrm{Bu}_{4} \mathrm{ZnLi}_{2}$ prepared by us (Figure 7). These results indicate that the ROP of 

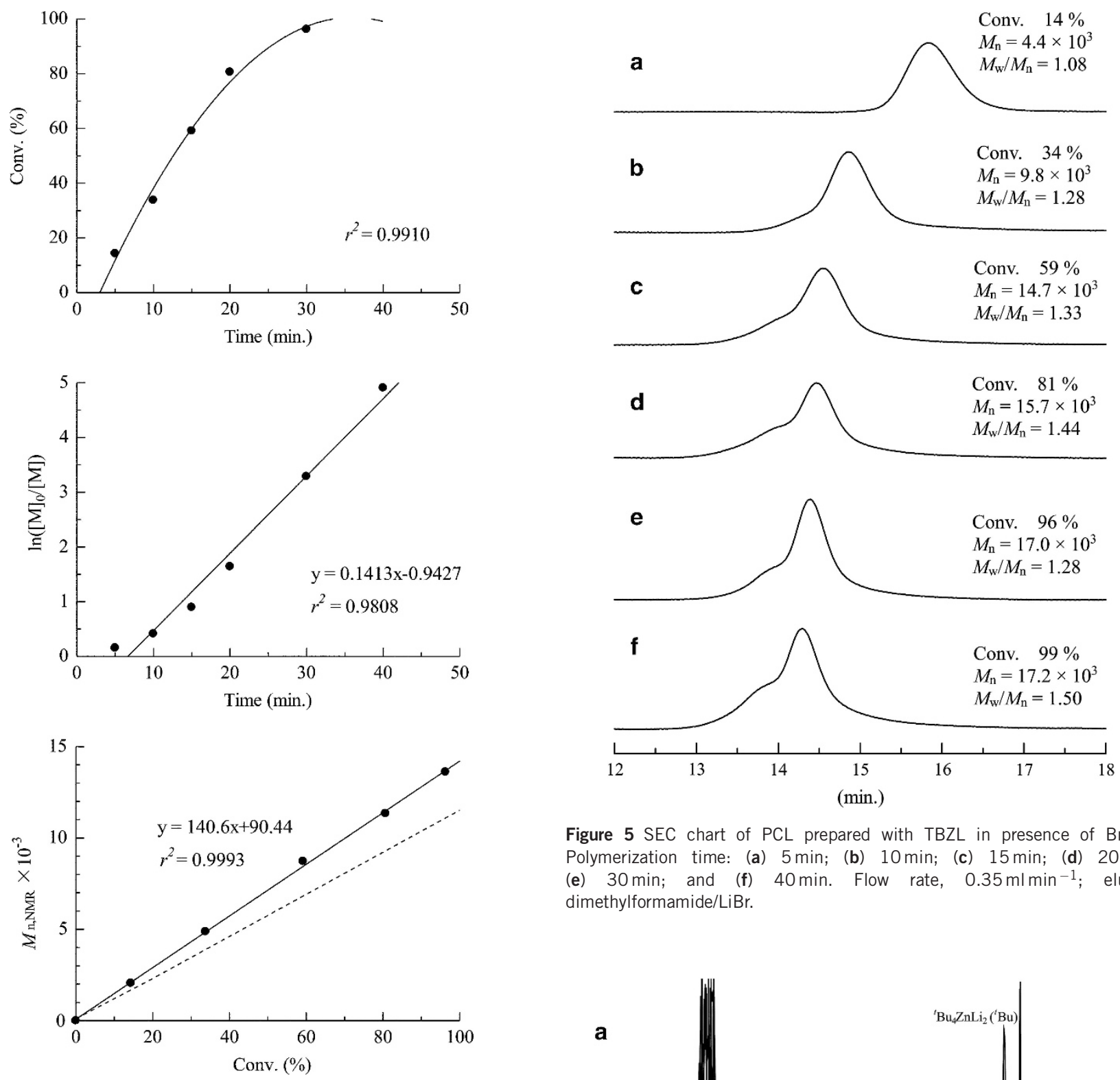

Figure 4 Plots of conversion (top) and $\ln \left([\mathrm{M}]_{0} /[\mathrm{M}]\right.$ ) (middle) versus time, and $M_{\mathrm{n}, \mathrm{NMR}}$ versus conversion (bottom; dashed line indicates theoretical line), for ROP of $\varepsilon$-caprolactone with TBZL in presence of $\mathrm{BnOH}$ (run 5).

$\varepsilon$-caprolactone is not catalyzed by ${ }^{t} \mathrm{Bu}_{2} \mathrm{Zn}$ and ${ }^{t} \mathrm{Bu}_{4} \mathrm{ZnLi}_{2}$ is the actual catalyst for the ROP of $\varepsilon$-caprolactone. Molecular weights calculated by ${ }^{1} \mathrm{H}$ NMR spectra were nearly twice as large as the theoretical values obtained when $\mathrm{BnOH}$ was added four times than TBZL (runs 5 and 10). In this case, not only $\mathrm{BnOH}$ and TBZL, but also $\varepsilon$-caprolactone should be considered. Decrease of TBZL caused low initiation efficiency owing to the difficulty of initiation than propagation in this case.

${ }^{1} \mathrm{H}$ and ${ }^{13} \mathrm{C}$ NMR spectra of ethyl acetate (as an $\varepsilon$-caprolactone model) or $\mathrm{BnOH}$ in the presence of an equimolar amount of the prepared TBZL were examined to clarify as to how the ${ }^{t} \mathrm{Bu}_{4} \mathrm{ZnLi}_{2}$ forms the actual active species. The ${ }^{1} \mathrm{H}$-and ${ }^{13} \mathrm{C}-\mathrm{NMR}$ spectra of ethyl acetate showed scarcely any changes, regardless of the presence of TBZL (Supplementary Figure S2). In contrast, the addition of TBZL

resulted in the loss of ${ }^{1} \mathrm{H}$ NMR signals from the hydroxyl protons of $\mathrm{BnOH}$ and broadening of the resonances from the methylene protons of $\mathrm{BnOH}$, with a downfield shift (Figure 8). Similarly, the ${ }^{13} \mathrm{C}-\mathrm{NMR}$

FEC chart of PCL prepared with TBZL in presence of $\mathrm{BnOH}$ Polymerization time: (a) $5 \mathrm{~min}$; (b) $10 \mathrm{~min}$; (c) $15 \mathrm{~min}$; (d) $20 \mathrm{~min}$ (e) $30 \mathrm{~min}$; and (f) $40 \mathrm{~min}$. Flow rate, $0.35 \mathrm{ml} \mathrm{min}^{-1}$; eluent, dimethylformamide/LiBr.

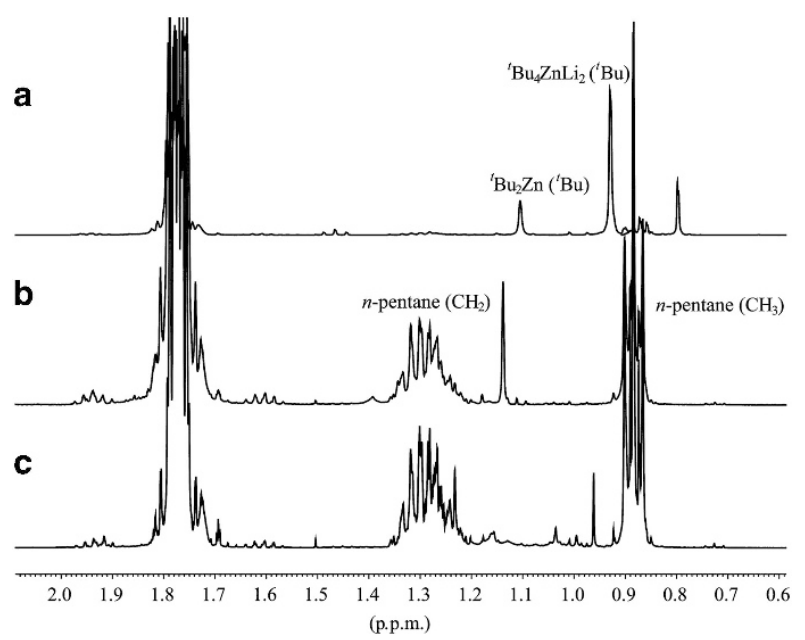

Figure $6{ }^{1} \mathrm{H}$ NMR spectra of (a) TBZL, (b) ${ }^{t} \mathrm{Bu}_{2} \mathrm{Zn}$, and (c) ${ }^{t} \mathrm{Bu}_{4} \mathrm{ZnLi} \mathrm{i}_{2}$ prepared by ourselves (in tetrahydrofuran- $d_{8}$ at $\mathrm{O}^{\circ} \mathrm{C}$ ). 
signals of the methylene carbons of $\mathrm{BnOH}$ exhibited a downfield shift. Similar observations have been reported for zinc complexes supported by maltolato ligands ${ }^{11}$ and zinc complexes supported by $\mathrm{N}, \mathrm{O}$ ketiminate ligands, ${ }^{12}$ which are used for the ROP of cyclic esters. It is therefore assumed that ${ }^{t} \mathrm{Bu}_{4} \mathrm{ZnLi}_{2}$ forms a complex with $\mathrm{BnOH}$, which initiates the ROP.

The ${ }^{1} \mathrm{H}$ NMR spectrum of TBZL in the presence of excess $\mathrm{BnOH}$ (4 eqiv) was recorded to confirm the hydrogen abstraction reaction of the hydroxyl group of $\mathrm{BnOH}$ with the tert-butyl group of TBZL (Figure 9). On addition of excess $\mathrm{BnOH}$ to the TBZL solution, the signals from the tert-butyl groups on TBZL disappeared. This suggests that the tert-butyl group reacted with the hydroxyl group on $\mathrm{BnOH}$ and volatilized as isobutane. A possible mechanism of the ROP of $\varepsilon$-caprolactone with TBZL in the presence of $\mathrm{BnOH}$ is shown in Scheme 2.

To clarify whether or not the induction period previously mentioned was caused by hydrogen abstraction and complex formation, ROP of $\varepsilon$-caprolactone was performed by adding $\varepsilon$-caprolactone after premixing TBZL and $\mathrm{BnOH}$ at $0{ }^{\circ} \mathrm{C}$ for $15 \mathrm{~min}$. The $\ln \left([\mathrm{M}]_{0} /\right.$

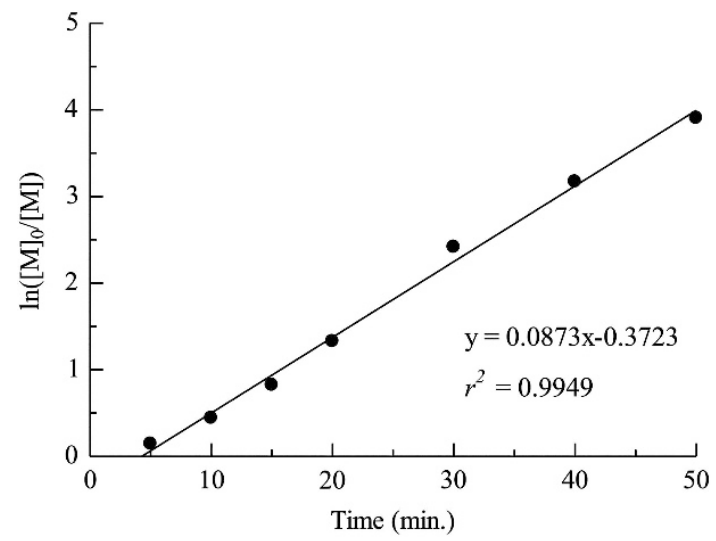

Figure $7 \ln \left([M]_{0} /[M]\right)$ versus time for ROP of $\varepsilon$-caprolactone with ${ }^{{ }^{t}} \mathrm{Bu}_{4} \mathrm{ZnLi}_{2}$, prepared by ourselves, in presence of $\mathrm{BnOH}$ (run 8).

a

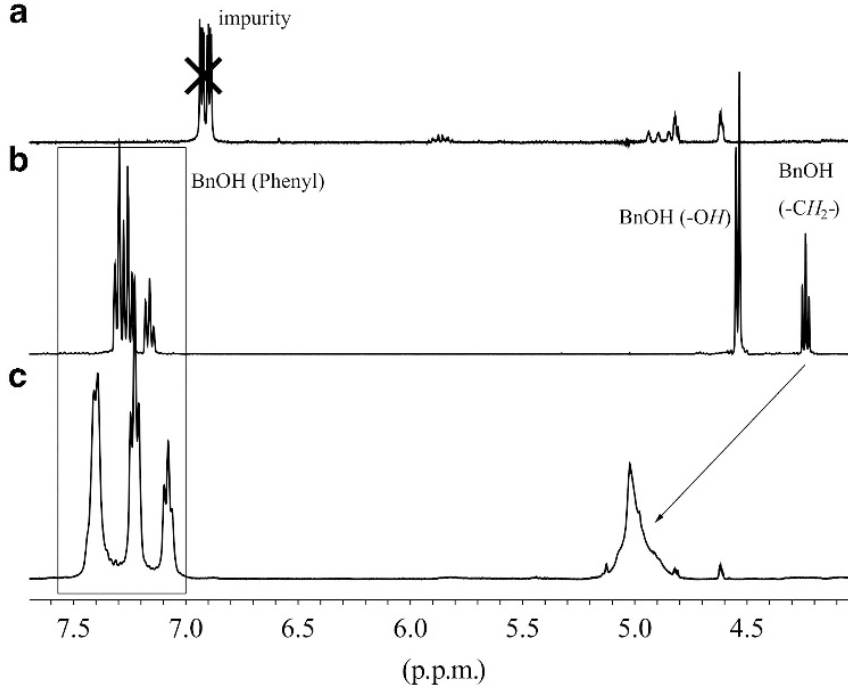

$[\mathrm{M}]$ ) versus time plots suggest that there was a significant induction period (Supplementary Figure S3). The induction period in the ROP of $\varepsilon$-caprolactone was not caused by hydrogen abstraction and complex formation between $\mathrm{BnOH}$ and TBZL. MeOH was premixed with TBZL instead of $\mathrm{BnOH}$ and a similar ROP induction period was observed. These results suggest that the induction periods in the ROP of $\varepsilon$-caprolactone were not caused by a sterically hindered benzyloxy group generated from $\mathrm{BnOH}$, but by the coordination between $\varepsilon$ caprolactone and a complex of $\mathrm{BnOH}$ and TBZL.

\section{CONCLUSIONS}

This system does not need a high polymerization temperature or long polymerization time and uses a metal compound that has little effect on the environment; PCL with a narrow molecular weight distribution can therefore be obtained under mild conditions. These results

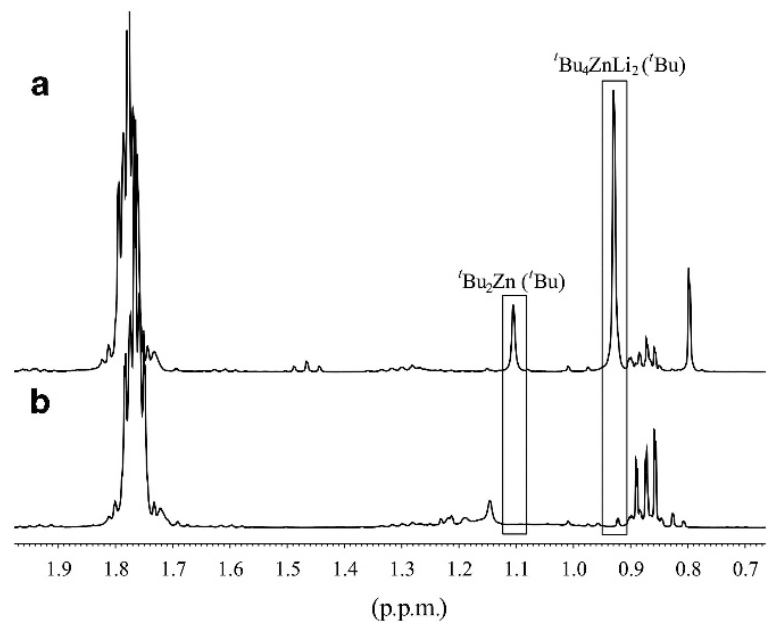

Figure $9{ }^{1} \mathrm{H}$ NMR spectra of (a) TBZL and (b) excess amount of $\mathrm{BnOH}$ and TBZL $\left(4 / 1\right.$, in tetrahydrofuran- $d_{8}$ at $\left.0{ }^{\circ} \mathrm{C}\right)$.

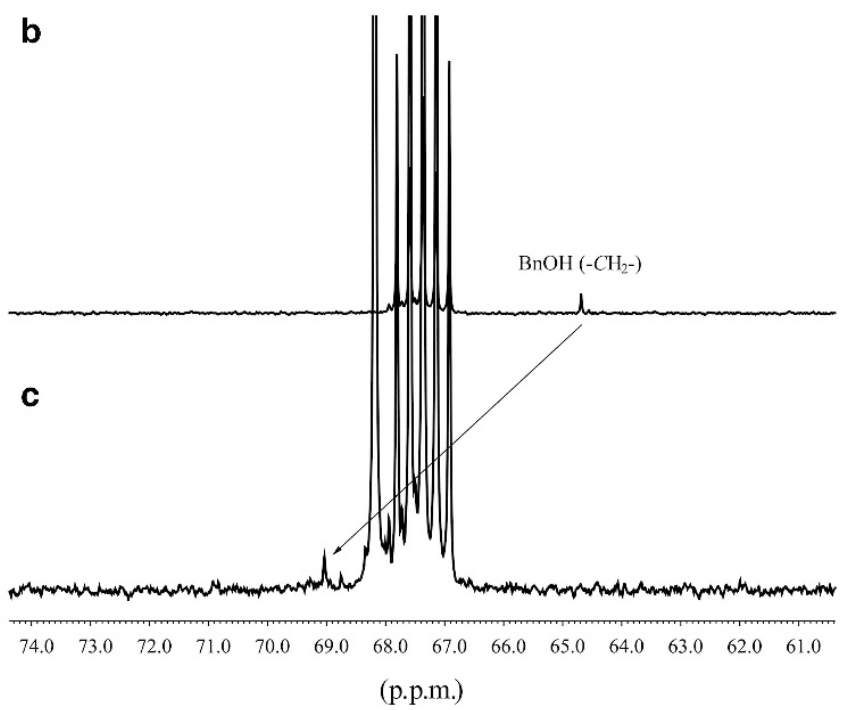

Figure $8{ }^{1} \mathrm{H}$ and ${ }^{13} \mathrm{C}$ NMR spectra of (a) TBZL, (b) $\mathrm{BnOH}$, and (c) equimolar mixture of $\mathrm{BnOH}$ and TBZL (in tetrahydrofuran- $d_{8}$ at $0^{\circ} \mathrm{C}$ ). 


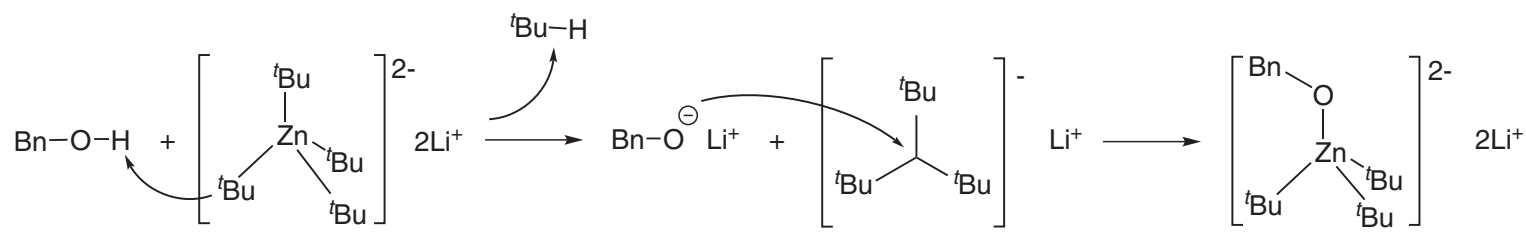

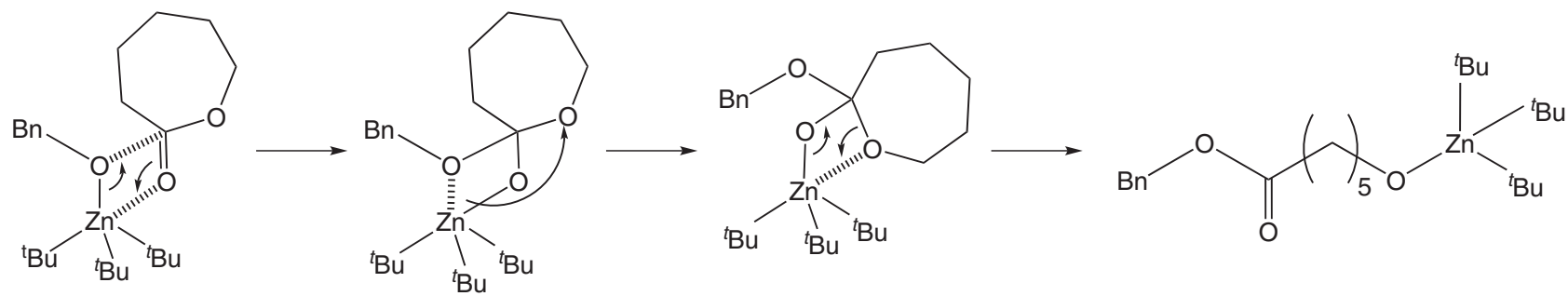

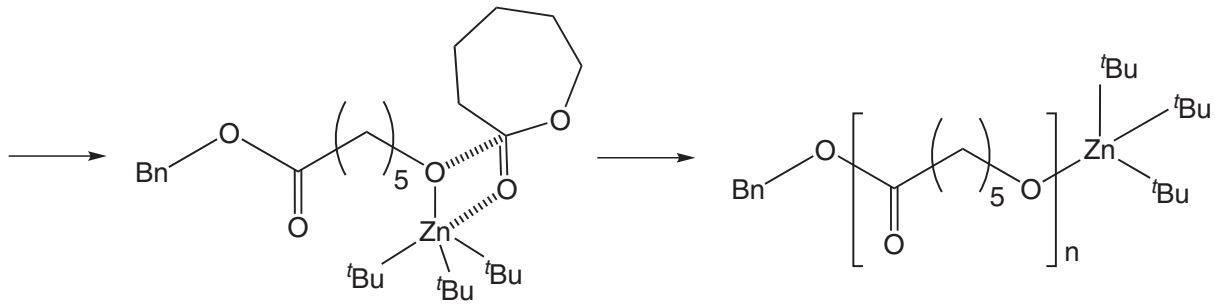

Scheme 2 Possible mechanism of ROP of $\varepsilon$-caprolactone with TBZL in presence of $\mathrm{BnOH}$.

demonstrate that TBZL is an excellent candidate for catalyzing rapid ROP of $\varepsilon$-caprolactone.

\section{ACKNOWLEDGEMENTS}

The authors thank Dr Tomoki Yabutani and Ms Yuka Sasaki of The University of Tokushima for technical support with the inductively coupled plasma optical emission spectroscopy and MALDI-TOFMS measurements.

1 Labet, M. \& Thielemans, W. Synthesis of polycaprolactone: a review. Chem. Soc. Rev. 38, 3484-3504 (2009).

2 Kitayama, T., Yamaguchi, H., Kanzawa, T. \& Hirano, T. Living ring-opening polymerization of $\varepsilon$-caprolactone with combinations of tert-butyllithium and bilky aluminium phenoxides. Polym. Bull. 45, 97-104 (2000).

3 Kobayashi, M., Matsumoto, Y., Uchiyama, M. \& Ohwada, T. A new chemoselective anionic polymerization method for poly( $N$-isopropylacrylamide) (PNIPAm) in aqueous media: design and application of bulky zincate possessing little basicity. Macromolecules 37, 4339-4341 (2004).

4 Uchiyama, M., Kobayashi, Y., Furuyama, T., Nakamura, S., Kajihara, Y., Miyoshi, T., Sakamoto, T., Kondo, Y. \& Morokuma, K. Generation and suppression of 3-/4functionalized benzynes using zinc ate base (TMP - Zn -ate): new approaches to multisubstituted benzenes. J. Am. Chem. Soc. 130, 472-480 (2008).
5 Furuyama, T., Yonehara, M., Arimoto, S., Kobayashi, M., Matsumoto, Y. \& Uchiyama, M. development of highly chemoselective bulky zincate complex, $t \mathrm{Bu}_{4} \mathrm{ZnLi}_{2}$ : design, structure, and practical applications in small-/macromolecular synthesis. Chem. Eur. J. 14, 10348-10356 (2008).

6 Hirano, T., Furutani, T., Saito, T., Segata, T., Oshimura, M. \& Ute, K. Isotactic-specific anionic polymerization of $\mathrm{N}$-isopropylacrylamide with dilithium tetra-tert-butylzincate in the presence of a fluorinated alcohol or Lewis acid. Polymer 53, 4961-4966 (2012).

7 Duda, A. \& Penczek, S. Polymerization of $\varepsilon$-caprolactone initiated by aluminum isopropoxide trimer and/or tetramer. Macromolecules 28, 5981-5992 (1995).

8 Dubois, Ph., Ropson, N., Jérôme, R. \& Teyssié, Ph. Macromolecular engineering of polylactones and polylactides. 19. kinetics of ring-opening polymerization of $\varepsilon$-caprolactone initiated with functional aluminum alkoxides. Macromolecules 29 1965-1975 (1996).

9 Stevels, W. M., Ankone, M. J. K., Dijkstra, P. J. \& Feijen, J. Kinetics and mechanism of $\varepsilon$-caprolactone polymerization using yttrium alkoxides as initiators. Macromolecules 29, 8296-8303 (1996)

10 Kakuchi, R., Tsuji, Y., Chiba, K., Fuchise, K., Sakai, R., Satoh, T. \& Kakuchi, T. Controlled/living ring-opening polymerization of $\delta$-valerolactone using triflylimide as an efficient cationic organocatalyst. Macromolecules 43, 7090-7094 (2010).

11 Petrus, R. \& Sobota, P. Zinc complexes supported by maltolato ligands: synthesis, structure, solution behavior, and application in ring-opening polymerization of lactides. Organometallics 31, 4755-4762 (2012).

12 Chen, H. L., Chuang, H. J., Huang, B. H. \& Lin, C. C. Inorg. ring-opening polymerization of $\varepsilon$-caprolactone, $\beta$-butyrolactone and lactides by $\beta$-ketiminate pyrazolonate zinc complexes: preparation and characterization. Chem. Commun. 35, 247-251 (2013).

Supplementary Information accompanies the paper on Polymer Journal website (http://www.nature.com/pj) 